Revista Destaques Acadêmicos, Lajeado, v. 12, n. 3, 2020. ISSN 2176-3070

DOI: http://dx.doi.org/10.22410/issn.2176-3070.v12i3a2020.2621

http://www.univates.br/revistas

\title{
SEXUALIDADE E VULNERABILIDADE ÀS INFECÇÕES SEXUALMENTE TRANSMISSÍVEIS NA PERCEPÇÃO DE ESTUDANTES DE UMA ESCOLA PÚBLICA MATOGROSSENSE
}

\author{
Mônica Strege Medici ${ }^{1}$, Marcelo Franco Leão
}

\begin{abstract}
Resumo: A sexualidade humana compreende um conjunto de comportamentos que envolve aspectos como o gênero, a orientação sexual, a identidade e expressão de gênero. Apesar de complexo e necessário por fazer parte da natureza humana, o tema é pouco debatido em âmbito familiar e escolar. Além disso, a falta de informação e de compreensão sobre o assunto faz com que os adolescentes fiquem vulneráveis a problemas como as infecções. O objetivo do estudo foi identificar, junto a estudantes do Ensino Médio de uma escola pública mato-grossense, as principais fontes de informações sobre sexualidade, os níveis de informação que possuem sobre as Infecções Sexualmente transmissíveis (ISTs) e o quanto estão vulneráveis a elas. O presente estudo ocorreu no quarto semestre letivo de 2019 e envolveu 62 estudantes do $1^{\circ}$ ano do Ensino Médio da Escola Estadual Professora Maria Esther Peres, município de Vila Rica/MT. Tratase de uma pesquisa descritiva e exploratória que utilizou um questionário constituído por 16 questões que serviram para avaliar a atividade. Com o desenvolvimento deste trabalho foi possível identificar características gerais dos estudantes, como lidam com a sexualidade, seus conhecimentos sobre ISTs, as formas de contágio e prevenção que conhecem. Portanto, cada vez mais é preciso refletir sobre o papel da escola e da família diante da formação do indivíduo no que tange o tema sexualidade e prevenção de ISTs e nesse sentido preservar saúde pública.
\end{abstract}

Palavras-chave: Adolescência. Educação sexual. IST. Prevenção.

1 Graduação em Licenciatura em Ciências Biológicas e Bacharel em Ecologia (Centro Universitário de Várzea Grande). Especialização em Ensino de Biologia (Universidade Candido Mendes). Professora efetiva na Escola Estadual Professora Maria Esther Peres (SEDUC/MT), onde ministra as disciplinas de ciências e biologia para o Ensino Fundamental e Médio. Membro do Grupo de Pesquisa Ensino de Ciências e Matemática no Baixo Araguaia (EnCiMa).

2 Graduação em Química Licenciatura Plena (UNISC) e em Licenciatura em Física (UNEMAT). Especialização em Orientação Educacional (DOM ALBERTO) e em Relações Raciais e Educação na Sociedade Brasileira (UFMT). Mestrado em Ensino (UNIVATES) e Doutorado em Educação em Ciências: Química da Vida e Saúde (UFRGS). Professor de Química no Departamento de Ensino do IFMT Campus Confresa. Membro do Grupo de Pesquisa Ensino de Ciências e Matemática no Baixo Araguaia (EnCiMa). 


\section{INTRODUÇÃO}

A adolescência é um período da vida marcado por transformações, pois consiste na transição entre a infância e a vida adulta. Nesse período da vida, o indivíduo se depara com inúmeras mudanças, dentre elas destacam-se as mudanças físicas, psicológicas e comportamentais. Para lidar com todas estas mudanças é necessário que o indivíduo tenha acesso a informações referentes ao momento transitório dessa fase da vida, para assim aprender a lidar com as mesmas (AQUINO; MARTELLI, 2012).

Um fato marcante da adolescência é a ocorrência da puberdade que, de acordo com Coutinho (2011) é um fenômeno marcado por fatores biológicos da adolescência, possibilitando o completo crescimento do corpo, bem como e a maturação hormonal que asseguram a capacidade de reprodução e a perpetuação da espécie. Por ser um período marcado por transformações significativas, destacam-se dois agentes fundamentais para que o indivíduo se sinta seguro: em primeiro lugar a família e em seguido a escola. Essas duas organizações sociais precisam estar preparadas e disponíveis para oferecer as informações necessárias para que o indivíduo saiba lidar com as referidas mudanças de uma forma tranquila.

No entanto, o que vemos na sociedade contemporânea é um distanciamento dos adolescentes em relação às suas respectivas famílias e, como se não bastasse, a escola retroagindo no âmbito da discussão e formação sobre a sexualidade, prova disso são as novas políticas voltadas para a educação que apresentam um retrocesso pautado no conservadorismo religioso, que pretende tirar da escola a autonomia em debater importantes assuntos como esse.

Conforme destaca o Projeto de Lei $N^{\circ} 7.180 / 2014$, em seu Art.2 ${ }^{\circ}$ : $\mathrm{O}$ Poder Público não se imiscuirá no processo de amadurecimento sexual dos alunos nem permitirá qualquer forma de dogmatismo ou proselitismo na abordagem das questões de gênero" (BRASIL, 2014). Sabe-se que a escola pode ser em muitos casos a única fonte segura de informação e, portanto, essa instituição não pode ser silenciada, tampouco se omitir de seu papel formativo afim de evitar que indivíduo busque fontes alternativas para poder sanar suas dúvidas e encontre informações equivocadas.

Nessa linha de raciocínio, é preciso considerar que os adolescentes comumente recorrem às mídias, aos amigos ou a outras fontes informais para obter respostas frente suas dúvidas sobre a sexualidade. Nesse processo formativo, fatalmente pode ocorrer que encontrem informações distorcidas, o que pode acarretar em danos à sua formação (MEIRA; SANTANA, 2014).

Em seus estudos, Santana (2005) afirma que a publicidade se destaca pelo seu aspecto persuasivo e, sendo assim, exerce domínio e desejo latentes pelo consumismo, ou seja, pouco está preocupada com as opiniões que forma, desde que se tornem consumidores. Nesse sentido, compreendemos que o 
domínio das mídias sobre os jovens vai para além de convencê-lo a adquirir determinado produto, incentivando-os a adotar determinado comportamento.

Cabe ressaltar que pesquisas recentes apontam para o fato de os adolescentes ficarem boa parte de seus dias conectados e assim, sujeitos a uma gama de conteúdos, no entanto, nem todos são benéficos para o desenvolvimento dos sujeitos, principalmente em momentos que o indivíduo busca respostas a questionamentos voltados a seu corpo. Neste momento as informações não podem ser genéricas, elas precisam levar em conta as especificidades individuais (NUNES, 2000).

Diante da dificuldade que o indivíduo tem em abordar determinados assuntos, principalmente aqueles voltados às transformações do corpo, muitas vezes por este assunto representar um "tabu", ou até mesmo pela insegurança dos pais que se omitem diante destes aspectos, as dúvidas são trazidas à escola. De acordo com Freire (1977), a educação é um saber fazer que só acontece no convívio social. O conhecimento não é apenas um simples acúmulo de conteúdos, mas sim, uma atividade permanente e sistematizada da sociedade humana.

Diante disso, é importante destacar que o papel da educação vai além dos conteúdos previamente programados, ela necessita ser dialógica e dinâmica, um processo no qual todos os sujeitos envolvidos sintam-se enredados, possibilitando assim a formação integral. Ainda de acordo com Freire (1999), a educação é uma atividade que se desenvolve à medida que o homem se propõe a responder aos desafios de maneira crítica e transformadora. Portanto, é papel da escola estimular o indivíduo a conhecer-se em todos os sentidos para que assim, o mesmo possa atuar na sociedade de forma crítica, responsável e com ética, pois aquele que aprende a se respeitar, respeitará o outro.

Além de concordar com o pensamento supracitado, Nunes (2000) vai além, e destaca que é papel da escola a educação sexual, ou seja, o trabalho de informações e orientação sobre a sexualidade. Segundo a autora, essa ação educativa precisa estar pautada em ajudar crianças e adolescentes a terem uma visão positiva swereobre a sexualidade, possibilitando a elaboração de seus próprios valores a partir de um pensamento crítico, a compreensão de seu comportamento e o do outro, e a tomarem decisões responsáveis sobre sua vida sexual.

Frente ao exposto, esse estudo teve por objetivo identificar quais as principais fontes de informações acerca da sexualidade, de estudantes do Ensino Médio de uma escola pública no município de Vila Rica-MT, bem como, diagnosticar os níveis de informação acerca das Infecções Sexualmente transmissíveis (ISTs) e identificar o quanto estão vulneráveis a elas. 


\section{SEXUALIDADE E INFECÇÕES SEXUALMENTE TRANSMISSÍVEIS (ISTs)}

O desenvolvimento humano é atrelado ao desenvolvimento sexual em todas as etapas da vida, antes mesmo da própria infância. A expressão da sexualidade é iniciada desde antes do nascimento do bebe, pois ao se deparar como uma mulher grávida uma das perguntas mais recorrentes é: Qual o sexo do indivíduo? Freud (1969) aponta que as ideias populares acerca da inexistência da sexualidade infantil reproduzem uma concepção equivocada, na qual considera-se a sexualidade como fragmentada na vida do indivíduo, restrita e definida ao nascer, inerente ao sexo biológico masculino ou feminino, desconsiderando-a tal qual manifestação natural que permeia toda sua existência.

Vygotsky (1991) ressalta que o desenvolvimento infantil em uma abordagem dialética se caracteriza:

[...]pela periodicidade e desigualdade no desenvolvimento de diferentes funções, metamorfose ou transformação qualitativa de uma forma em outra, embricamento de fatores internos e externos, e processos adaptativos que superam os impedimentos que a criança encontra (VYGOTSKY, 1991, p. 51).

Conforme destaca o autor supracitado, desde a infância o desenvolvimento do indivíduo é influenciado tanto por fatores internos quanto externos, portanto ambos exercem influência sobre a construção do indivíduo, constituindo-o em várias dimensões como ser biológico, social e cultural (VYGOTSKY, 1991). Neste sentido, entendemos que na adolescência as transformações e os conflitos passam a ser mais evidentes, pois, nessa etapa, os sujeitos firmam, legitimam e justificam sua sexualidade, levando a compreensão da sexualidade como um processo histórico-cultural.

Conforme afirma Meira e Santana (2014, p. 169): “A perspectiva histórico-cultural entende a formação e o desenvolvimento humano nas dimensões sociais, culturais e políticas, sendo esses aspectos determinantes na construção da sexualidade". Desde a infância a criança é sujeita a experiencia sua sexualidade e transformações anatômicas. Ao mesmo tempo, ela passa a vivenciar a erotização por meio da sua convivência social, pelo acesso às letras musicais, filmes, desenhos, novelas, noticiários entre os mais diversos conteúdos veiculados na mídia, especialmente na Internet.

Esse acesso às mídias, associado ao próprio desenvolvimento do corpo, despertará na criança e no adolescente curiosidades, dúvidas e até mesmo um padrão de comportamento (MEIRA; SANTANA, 2014). As dúvidas acerca da sexualidade naturalmente serão levadas para o âmbito familiar e escolar, ou seja, é importante que o indivíduo tenha a resposta à sua pergunta, pois ao se 
furtar debater o tema a dúvida perdurará e a fará buscar respostas em outras fontes.

A educação sexual não é um assunto atual na educação brasileira, ao fazer uma breve retrospectiva histórica vemos que este tema permeia o contexto escolar há décadas. Ao considerarmos a educação sexual praticada nas escolas brasileiras, constatamos que esta prática não se restringe apenas às últimas décadas, ao contrário, constitui uma preocupação que remonta às primeiras décadas do século passado (AQUINO; MARTELLI, 2012).

Nos anos 20 e 30 do século XX, educação sexual já era uma preocupação para médicos, intelectuais, professores com uma abordagem higienista voltada para a saúde. Aquino e Martelli (2012) apontam que em 1928 realizou-se o Congresso Nacional de Educadores, no qual foi aprovado o Programa de Educação Sexual a ser desenvolvido com crianças acima de onze anos de idade. Ampliava-se então o debate nas escolas acerca da temática que era vista como natural pela sociedade da época, pois neste período a educação brasileira passava por significativas mudanças e a escola de educação básica ampliava seu protagonismo. No entanto, aconteceu o golpe militar em 1964 e as escolas retrocederam, os professores foram submetidos à censura e à repressão:

No início da ditadura militar, em 1965, uma portaria do secretário de Estado dos Negócios da Educação do Estado de São Paulo proibiu professores do ensino secundário, em especial os de Biologia e de Sociologia, de exporem nas escolas sobre a sexualidade e sobre a contracepção (WEREBE, 1998, p. 174).

Não só por essa portaria, mas também pela própria história de repressão, sabemos que a ditadura militar impôs um comportamento conservador e uma política repressora para a sociedade. As escolas passaram a deixar essa temática de lado e gradativamente silenciaram o diálogo sobre a sexualidade, entre tantos outros temas relevantes à sociedade. Ainda sobre o período histórico, Lira (2010) ressalta que durante a ditadura as classes dominantes buscavam moldar a educação brasileira de acordo com seus interesses econômicos, nesse sentido as disciplinas eram analisadas para que a escola reproduzisse um modelo educacional voltado aos seus interesses.

Com a redemocratização do ensino após golpe militar, a educação é reconfigurada e foi construído um documento de extrema relevância, a Lei de Diretrizes e Bases da Educação Nacional 9394/96 (BRASIL, 1996). Desde então, a escola passa a tratar o assunto sexualidade por meio de uma perspectiva clara e objetiva. Em 1996, essa terceira e mais recente Lei educacional foi aprovada, que logo em seguida deu origem aos Parâmetros Curriculares Nacionais (PCN).

Este último documento citado acima teve por objetivo orientar as escolas na reformulação de propostas pedagógicas, visando a melhorias das práticas e a coerência dos investimentos no sistema educacional brasileiro (BRASIL, 2000). 
Dentre os dez cadernos nos quais os PCN se organizam, há um específico que aborda sobre a orientação sexual, propondo abordar o tema da sexualidade no ambiente escolar, como tema transversal incorporado por todas as disciplinas.

Como é um tema pertinente ao desenvolvimento humano é necessário desconstruir mitos e tabus em torno da sexualidade, o diálogo precisa ser naturalizado, voltado à formação do ser humano possibilitando que cada um atribua novos valores em relação à sexualidade. Por não ser um conceito estável permite ao indivíduo modificar seu modo de pensar, aceitando o pensamento diferente e fugindo dos padrões convencionais impostos por determinados segmentos sociais. Vasconcelos (1971, p. 111) afirma que:

Educação sexual é abrir possibilidades, dar informações sobre os aspectos fisiológicos da sexualidade, mas, principalmente, informar sobre suas interpretações culturais e suas possibilidades significativas, permitindo uma tomada lúcida de consciência. É dar condições para o desenvolvimento contínuo de uma sensibilidade criativa em seu relacionamento pessoal. Uma aula de educação sexual deixaria de ser apenas um aglomerado de noções estabelecidas de biologia, de psicologia e moral, que não acompanham a sexualidade naquilo que lhe pode dar significado e vivência autêntica: a procura mesmo da beleza interpessoal, a criação de um erotismo significativo do amor.

Conforme o autor supracitado, a educação é a ferramenta utilizada para demonstrar aos estudantes que é possível dizer não aos padrões préestabelecidos contribuindo para que aconteça uma formação integral do sujeito. Assim, ao longo de sua formação ele passa a exercer o papel de cidadão livre de preconceitos em relação às possibilidades de escolha, de condutas e/ou de comportamento mesmo não estando em consonância com a sua forma de viver (VASCONCELOS, 1971). Neste sentido, a educação desconstrói o preconceito principalmente a homofobia.

Presume-se que as ideias e informações variadas sobre o assunto estejam presentes no currículo escolar, com o intuito de contribuir para a construção dessa visão do corpo (MEIRA; SANTANA, 2014). Assim, espera-se que sejam discutidas em sala de aula diferentes abordagens sobre a sexualidade, bem como sua influência nos diferentes aspectos da existência humana (AQUINO; MARTELLI, 2012).

Os conflitos emergentes no período da adolescência são os temas voltados à sexualidade, ou seja, a puberdade que compreende o período de maturação biológica e psicológica de acordo com esse conjunto de mudanças é denominada sexualidade (MAIA; RIBEIRO, 2011). Os autores destacam que a sexualidade é um conceito amplo e histórico, representada de maneira diversa em cada cultura. Os componentes biológicos, psicológicos e sociais compõem a sexualidade que é expressa de maneira única em cada ser humano. 
Os efeitos da sexualidade são individuais, em alguns casos podem ser mais severos, para outros, esta vivência pode ocorrer sem grandes percalços, por isso é importante que a abordagem deste tema seja feita por pessoas próximas, capazes de estabelecer uma relação de confiança com os adolescentes sujeitos às mudanças. Os contextos familiar e escolar necessitam se constituir em dois ambientes abertos ao diálogo, no sentido de orientar e propiciar o estabelecimento da identidade desses sujeitos em formação (MAIA; RIBEIRO, 2011).

Em seus estudos, as autoras Moises e Bueno (2010) pontuam a responsabilidade de o sistema escolar promover a educação integral da criança e do adolescente, sendo necessária uma discussão da temática sexualidade de maneira a promover a educação sexual nas escolas. esta fala coaduna com Freire (1977), que defende o espaço educacional como fundamentalmente, de comunicação e diálogo.

Caso o(a) adolescente não consiga as informações necessárias de forma segura, passa a iniciar sua vida sexual sem as devidas precauções tornando-se vulnerável aos mais diversos tipos de ISTs, colocando sua saúde em risco e também a de seu parceiro(a). Neste texto usaremos a terminologia ISTs, pois de acordo com Brasil:

A terminologia Infecções Sexualmente Transmissíveis (IST) passa a ser adotada neste Protocolo, em substituição à expressão Doenças Sexualmente Transmissíveis (DST), em consonância com a utilização internacional empregada pela Organização Mundial da Saúde (OMS), pela Organização Pan--Americana da Saúde (Opas), pela sociedade científica e por alguns países. Nesse contexto, alerta-se a população sobre a possibilidade de ter e transmitir uma infecção, mesmo sem sinais e sintomas, o que aponta para estratégias de atenção integral, eficaz e resolutiva (BRASIL, 2015, p. 13).

Conforme destaca a citação apresentada, é de suma importância que o(a) adolescente, ao iniciar a sua vida sexual, entenda que são inúmeros os agentes etiológicos capazes de transmitir doenças e muitas vezes, por serem assintomáticas são potencialmente infectantes. Nesse sentido, é preciso ficar claro que a IST é uma infecção sexualmente transmissível e a DST por sua vez é a manifestação da doença, ou seja, quando há manifestação clínica (BRASIL, 2015). No caso, a vulnerabilidade consiste na exposição a riscos, pois a infecção pode ser transmitida sem que o portador da mesma sequer tenha conhecimento.

Embasados em tais informações, é possível afirmar que toda relação sexual desprotegida e a falta de informação podem ser riscos à saúde, o que consiste em vulnerabilidade. Essa constatação é confirmada pelo próprio Ministério da Saúde já a algum tempo ao afirmar que: 
A vulnerabilidade pode agregar diversas dimensões: a individual, que se relaciona aos comportamentos adotados pelo indivíduo e que pode favorecer oportunidade de se infectar, como por exemplo, o não uso do preservativo; a social, que implica questões econômicas e sociais que influenciam o aumento da violência sexual, prostituição e tráfico de drogas; a institucional, que se relaciona à ausência de políticas públicas que tenham por objetivo controle da epidemia em populações e/ou localidades (BRASIL, 2000, p. 6).

Em outras palavras, a escola tem papel preponderante na educação sexual no sentido de informar o adolescente para que o mesmo possa praticar sua sexualidade com segurança, sem exposição a riscos de doenças, com a valorização do corpo. Em muitas circunstancias a família é omissa em relação à sexualidade, pois ainda é vista como um "tabu" e nesse sentido o estudante tem na escola a única fonte segura de informação, portanto a escola precisa exercer seu papel assumindo seu compromisso social.

\section{PROCEDIMENTOS METODOLÓGICOS}

$\mathrm{O}$ presente estudo caracteriza-se como uma pesquisa descritiva e exploratória, de abordagem mista devido envolver dados quantitativos para ilustrar o pensamento dos investigados e assim analisar tais informações qualitativamente. Segundo Gil (2010), uma pesquisa do tipo descritivo e exploratório é aquela que possui por finalidade o levantamento de características, de populações, fenômenos ou experiências, bem apropriado para investigar a sexualidade e a vulnerabilidade dos estudantes investigados.

Ainda de acordo com o autor supracitado, o uso dessa abordagem possibilita o aprofundamento da investigação, bem como das questões relacionadas ao objeto de estudo e das suas relações, com a aproximação da situação estudada, buscando-se o que era comum, mas permanecendo, entretanto, aberta para perceber a individualidade e os significados múltiplos.

A investigação foi desenvolvida em uma escola pública do município de Vila Rica/MT, que fica distante aproximadamente, $1.300 \mathrm{Km}$ de Cuiabá/MT. Sua realização ocorreu durante o quarto bimestre do ano letivo de 2019, que foi finalizado no mês de janeiro de 2020 devido a reposição de um período de greve.

Os sujeitos da pesquisa são 62 estudantes do $1^{\circ}$ ano do Ensino Médio da Escola Estadual Professora Maria Esther Peres. Cabe ressaltar que todos eles são adolescentes/jovens entre a faixa etária entre 15 a 18 anos de idade. Cabe ressaltar que todos os cuidados éticos foram tomados, ainda mais se tratando de menores de idade, ou seja, o estudo teve anuência da instituição e autorização dos pais ou responsáveis para sua realização.

Como instrumento de coleta de dados foi utilizado um questionário impresso, constituído por 16 questões fechadas, sobre o gênero, idade, suas 
fontes de informação sobre sexualidade, se já namorou, se já iniciou a vida sexual, se sabe definir ISTs, quais ISTs conhecem, se considera vulnerável a elas, se as ISTs apresentam cura e quais são elas, as formas de contágio e os métodos de prevenção das ISTs.

Para analisar os resultados coletados, foi utilizada a metodologia conhecida como análise de conteúdos, cuja categorização foi pré-estabelecida, uma vez que os critérios de análise tinham sidos estabelecidos no momento da formulação do questionário de questões fechadas (BARDIN, 2012). Os dados foram agrupados por afinidade temática e apresentados da seguinte maneira: Características gerais dos estudantes investigados; Aspectos referente a como lidam com a sexualidade; Conhecimentos dos estudantes sobre ISTs; e Formas de contágio e prevenção das ISTs.

\section{RESULTADOS E DISCUSSÃO}

Os dados foram tabulados em percentuais e organizados em gráficos para melhor ilustração e compreensão dos leitores. A Figura 1 ilustra duas informações sobre as características dos investigados (sexo e idade).

Figura 1: Características gerais dos estudantes investigados.

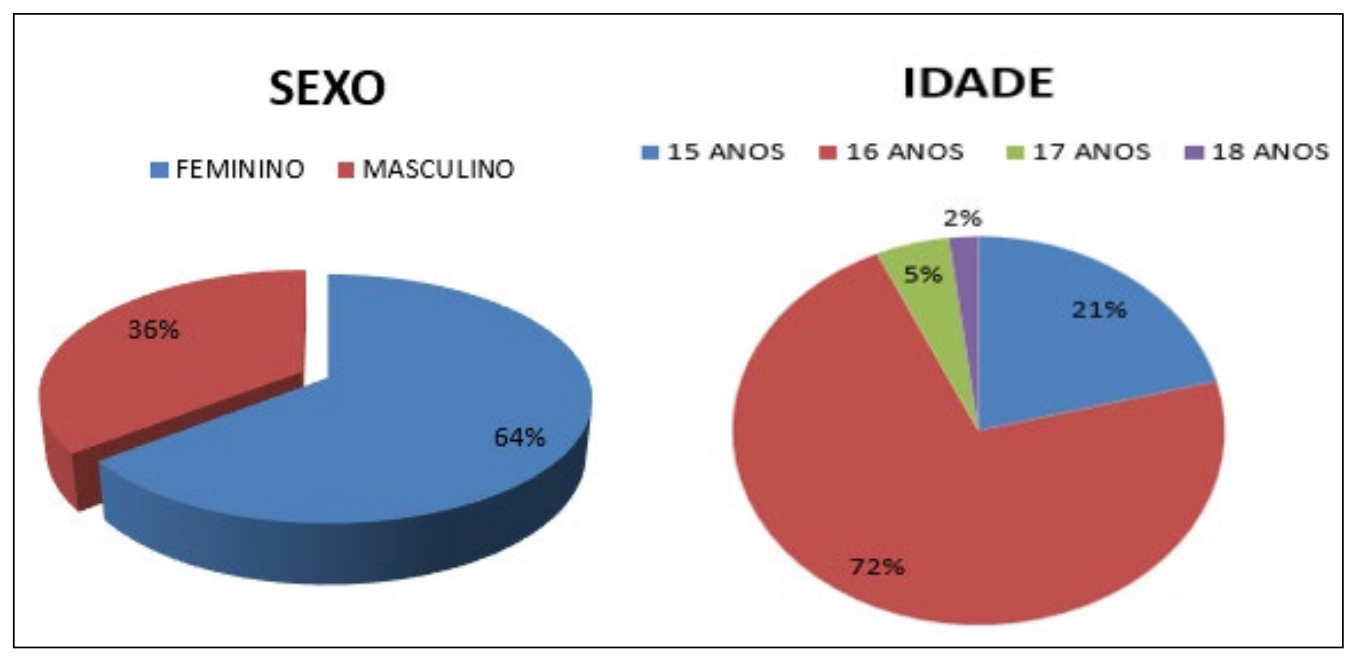

Fonte: Dados coletados na pesquisa (2020).

Pelos dados ilustrados na Figura 1, percebe-se que ampla maioria dos investigados são do sexo feminino, ou seja, $64 \%$ dos indivíduos entrevistados, enquanto $36 \%$ são do sexo masculino. Como o questionário foi aplicado no período matutino, observa-se que neste turno predominam as mulheres. Geralmente os homens dão preferência para estudar no período noturno ou até mesmo evadem da escola nessa etapa da vida buscando a inserção no mercado de trabalho. 
Um segundo dado, ilustrado na Figura 1, é a idade desses estudantes do $1^{\circ}$ ano do Ensino Médio. Percebe-se que estão na faixa etária entre 15 a 18 anos. De acordo com os dados do IBGE (2010), a vida sexual do adolescente brasileiro se inicia a partir dos 14 anos nas capitais e no Distrito Federal, a frequência de adolescentes matriculados no $9^{\circ}$ ano do Ensino Fundamental, do sexo masculino, que já iniciaram a prática sexual, foi de $43,7 \%$, enquanto que a proporção de indivíduos do sexo feminino, foi de 18,7\%, ou seja, é importante abordar este assunto na escola desde o Ensino Fundamental.

Os primeiros dados também conformam a necessidade levantada por Coutinho (2011) e Ribeiro (2010), de se abrir o diálogo sobre sexualidade ainda na adolescência, pois, segundo os autores, é o momento de transformações biológicas e psicológicas que afetam na formação da personalidade.

A Figura 2 ilustra os dados referentes a fontes de informações sobre sexualidade, se os estudantes já namoraram e se já iniciaram suas vidas sexuais.

Figura 2: Aspectos referente a como lidam com a sexualidade.

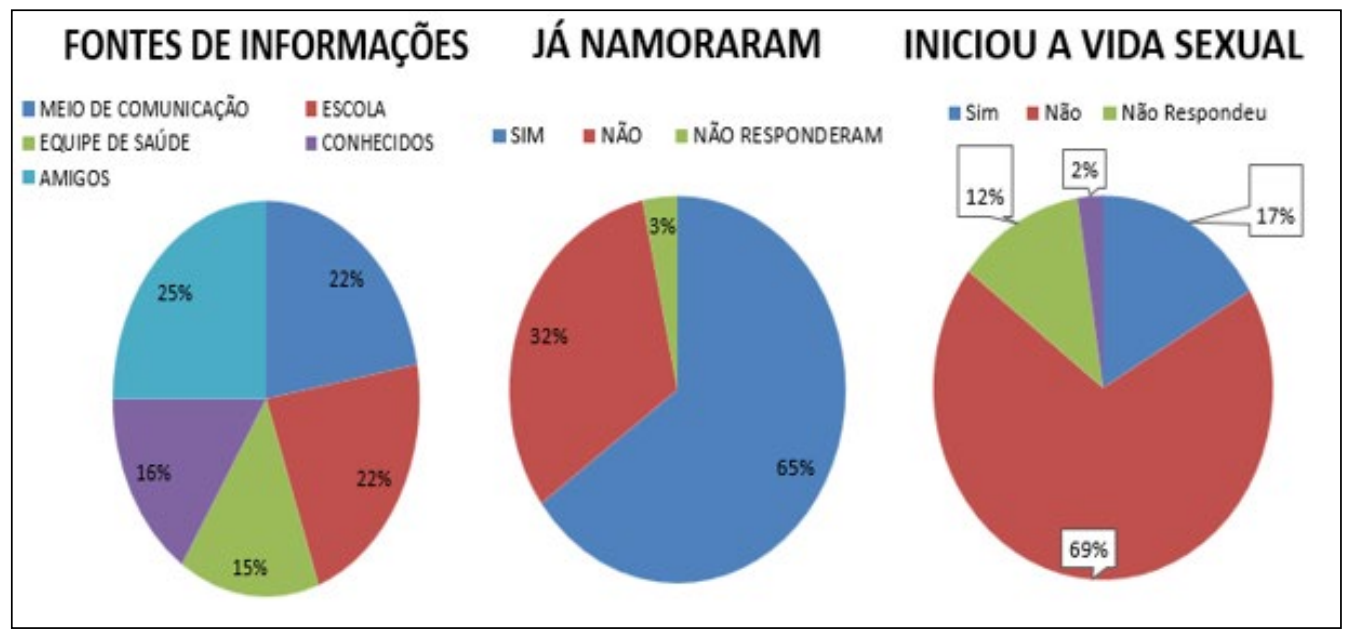

Fonte: Dados coletados na pesquisa (2020).

Ao serem questionados quanto as principais fontes de informação $25 \%$ dos entrevistados respondeu que buscam informações acerca do tema por meio de diálogos com os amigos, já $22 \%$ respondeu que utilizam como principais meios de informação a escola e o mesmo percentual diz que na família obtém as informações necessárias acerca do tema, enquanto $16 \%$ admite que busca se informar por meio de pessoas conhecidas e apenas $15 \%$ recorre aos profissionais da saúde. A somatória ultrapassa os $100 \%$, pois era possível marcar mais de uma opção.

Assim, podemos afirmar que o adolescente não tem uma única fonte de informação a respeito da sexualidade e que a família muitas vezes delega 
este papel a outros segmentos sociais (MAIA; RIBEIRO, 2011). É importante ressaltar que a escola precisa estar preparada para atender esta demanda, pois é impossível desvincular o tema do desenvolvimento do sujeito enquanto ser integral.

Tuckmantel (2011, p. 40) pressupõe que a construção da sexualidade de cada pessoa envolve "suas observações, os ensinamentos e informações adquiridos no contexto familiar, no senso comum, nos diálogos e no contexto escolar, incluindo neste último as concepções do docente referente à temática da sexualidade".

Ao fazer uma análise deste gráfico, identifica-se o quanto é necessário que a escola tenha autonomia, liberdade e preparo para abordar o tema de forma clara, sucinta e aberta, pois a escola é apontada pelos estudantes como uma fonte de informação segura. Em face desta afirmação é necessário combater o cerceamento e a censura da escola, como propõe o projeto em trâmite no Congresso Federal, o "Escola sem partido" que, conforme Britto (2019), adota uma lógica que predispõe à escola de monitoramento.

Neste sentido, o projeto "Escola sem partido" fere a Constituição Federal em relação ao artigo $5^{\circ}$, o qual assegura a livre manifestação do pensamento, vedado o anonimato; a inviolabilidade da liberdade de consciência e de crença; assim como a livre expressão da atividade intelectual, artística, científica e de comunicação, independentemente de censura ou licença e de intimidação dos docentes, portanto retirar a liberdade e controlar a atuação do professor principalmente em assuntos voltados a sexualidade, é também privar o adolescente de uma importante fonte de informação, configurando-se em um dos equívocos deste projeto de lei (BRASIL, 1988; BRITTO, 2019).

Ainda de acordo com a Figura 2, observa-se que $65 \%$ dos sujeitos da pesquisa já namoram, ou seja, estão dando os primeiros passos rumo ao início da vida sexual, comportamento normal da faixa etária e do contexto escolar, nesta fase da vida, quando o interesse pelo sexo oposto passa a ser mais evidente, considerando o desenvolvimento humano. Conforme destaca Foucault (1988, p. 101):

Nessa lógica podemos estabelecer que a relação entre o desenvolvimento humano, entendido aqui sob a ótica históricocultural, e a sexualidade se dá com bases em que a sexualidade é uma invenção da sociedade, já que se compõem historicamente e, segundo algumas estratégias e saberes, favorecem "a estimulação dos corpos, a intensificação dos prazeres, a incitação ao discurso, a formação dos conhecimentos, o reforço dos controles das resistências" (FOUCAULT, 1988, p. 101).

Os dados acima coadunam com as palavras do autor, pois o desenvolvimento humano perpassa por diversas fases e constantemente é influenciada por uma perspectiva sociocultural, como o contexto escolar reúne 
diversos indivíduos em fase de formação comumente terão um comportamento semelhante (FOUCAULT, 1988).

Assim, é necessário que a escola traga este debate para que o estudante tenha disponível a gama de informações necessária para preservar sua saúde e ter capacidade de exercer sua sexualidade de forma segura. De forma alguma a escola tem a pretensão de substituir a função da família, mas sim em constituir uma alternativa para auxiliar o estudante a vivenciar esta fase da melhor maneira possível. Em suma, pela mediação da escola, dá-se a passagem do saber espontâneo ao saber sistematizado, da cultura popular à cultura erudita." (SAVIANI, 1992, p. 29).

Um outro aspecto apresentado na Figura 2 é sobre a iniciação na vida sexual. Dentre os sujeitos da pesquisa, $69 \%$ respondeu que não iniciou a vida sexual, enquanto $17 \%$ afirmou que sim, $12 \%$ não respondeu a essa pergunta e outros $2 \%$ marcou mais de uma alternativa. Werebe (1998, p. 163) destaca que "uma autêntica educação sexual deve ter objetivos amplos: oferecer à criança e aos jovens a possibilidade de compreender as dimensões e a significação da sexualidade, de maneira a integrá-la positivamente na personalidade, a contribuir para que possam realizar projetos de vida pessoal e social como seres sexuados".

Considerando a faixa etária dos entrevistados e comparando os dados obtidos com outras pesquisas realizadas é possível afirmar que os adolescentes que ainda não iniciaram a vida sexual poderão iniciá-la nos próximos anos, pois Sousa et al. (2017), apoiado em estudo feito sobre o tema, alerta para o fato de os adolescentes estarem iniciando precocemente a vida sexual, principalmente em relação às do sexo feminino, que acusaram um acréscimo de dois anos, em média..

Nessa linha de pensamento, concordando com Sousa et al. (2017), é importante que a escola passe a inserir este tema desde o início do ensino fundamental e gradativamente, avançar na medida que os estudantes apresentem suas dúvidas de acordo com o desenvolvimento humano. Os Parâmetros Curriculares Nacionais apontam a escola como fundamental nesta etapa da vida sexual:

A escola, sendo capaz de incluir a discussão da sexualidade no seu projeto pedagógico, estará se habilitando a interagir com os jovens a partir da linguagem e do foco de interesse que marca essa etapa de suas vidas e que é tão importante para a construção de sua identidade (BRASIL, 2000, p.297).

Em outras palavras, a escola deve estar preparada para interagir com os adolescentes no sentido de orientá-los a exercer sua sexualidade de forma livre e segura, oferecendo as informações necessárias para manutenção da integridade da saúde (BRASIL, 2000). Por isso a necessidade de discutir as ISTs. 
Assim, a Figura 3 ilustra os dados referente a vários aspectos relacionados a ISTs.

Figura 3: Conhecimentos dos estudantes sobre ISTs.

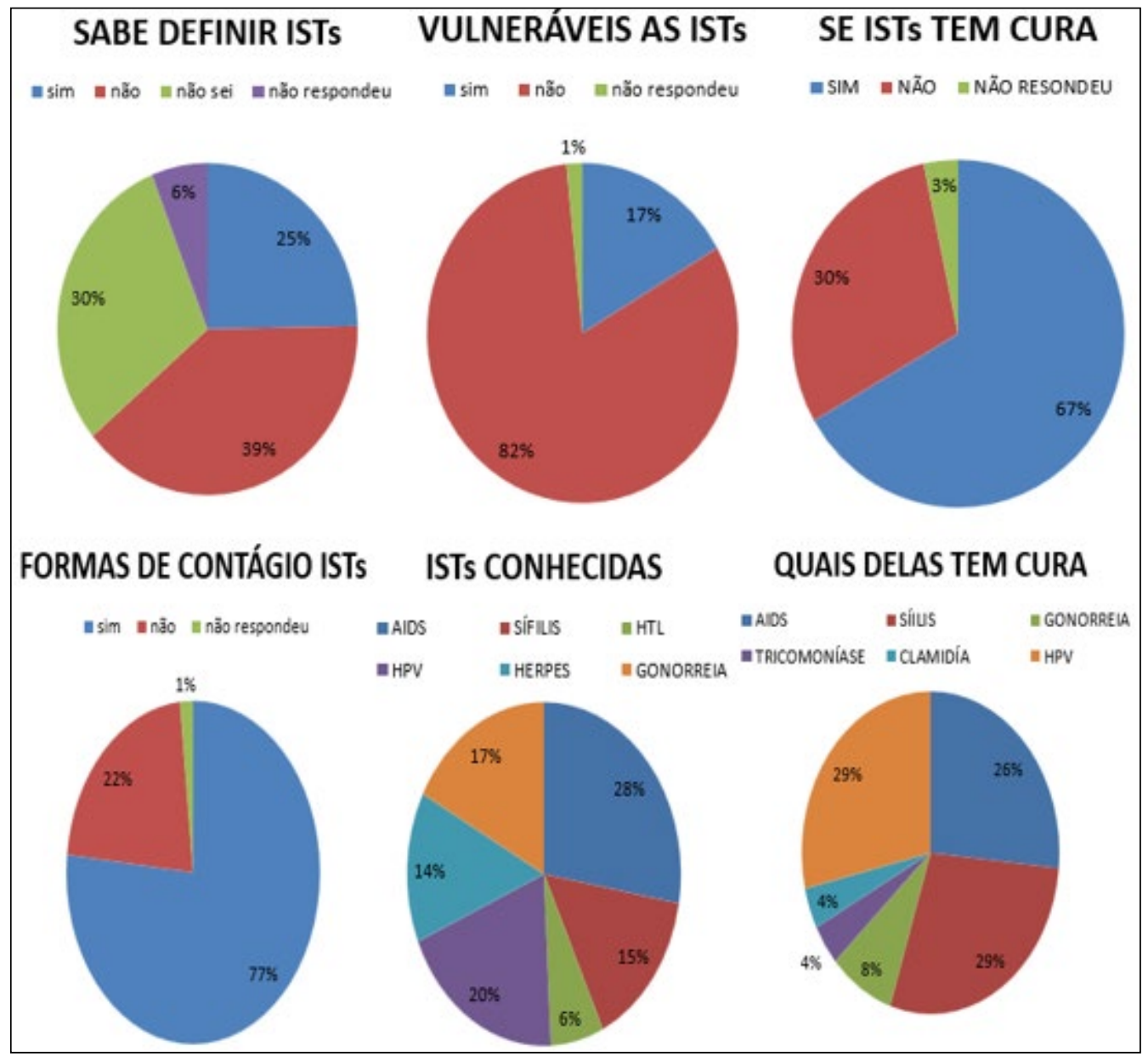

Fonte: Dados coletados na pesquisa (2020).

Ao serem questionados se sabem definir uma ISTs, 39\% respondeu não, $30 \%$ não soube responder, $25 \%$ afirma saber e $6 \%$ não respondeu à pergunta. Ao analisar os dados obtidos com a pesquisa é possível fazer a seguinte análise que a escola é o espaço adequado para discutir sobre sexualidade. Conforme afirma Vieira, Coutinho e Saraiva (2016, p. 41): “A escola é o local onde deve completar a formação do aluno, transmitindo valores, atitudes, reforçando comportamentos e crenças. É indispensável informar e orientar os jovens quanto a uma vida sexual mais segura e responsável". 
Os autores supracitados trazem um importante contraponto que deve ser analisado em um planejamento pedagógico, a escola está posta para a sociedade como um meio complementar de formação do sujeito, ou seja na dificuldade que os pais tenham referente a determinado tema a escola deve entrar com o intuito de preencher a lacuna, neste sentido os adolescentes e jovens sentem-se amparados e seguros e se desenvolvem integralmente (VIEIRA; COUTINHO; SARAIVA, 2016).

A respeito de o seu comportamento sexual ser encarrado como comportamento de risco os estudantes se mostraram seguros, pois, $82 \%$ respondeu que não está sujeito a risco, $17 \%$ admite não saber e $1 \%$ optou por não responder. Neste sentido, Vieira, Coutinho e Saraiva (2016, p. 22) ressaltam que:

A confiança no parceiro, principalmente das mulheres, é destacada na literatura como uma das razões mais comuns para abandono do comportamento preventivo. No lugar do preservativo, usam a própria fidelidade, a confiança e o conhecimento do parceiro como fantasiosa forma de prevenção.

É um comportamento natural do adolescente sentir-se seguro diante das ISTs, bem como de qualquer outro problema atrelado à sexualidade, no entanto outro fator deve ser levado em consideração, pois ao analisar este gráfico apenas, a resposta inicialmente pode parecer alarmante, mas ao considerar $\mathrm{o}$ gráfico a seguir, identifica-se essa segurança devido à não atividade sexual, pois, dentre os sujeitos entrevistados, $69 \%$ afirma não ter vida sexual ativa.

Sobre se conhece quais ISTs têm cura, $67 \%$ dos sujeitos participantes da pesquisa afirmam que conhecem as mesmas que têm cura e $30 \%$ não conhece as ISTs que tem cura e 3\% não responderam à pergunta. $\mathrm{O}$ fato de um grande número de estudantes afirmarem conhecer as ISTs que tem cura, demonstra um fator positivo. É importante destacar que, ainda que a maioria afirme conhecimento sobre ISTs e formas de contágio, a escola não pode se furtar à abordagem curricular deste tema, pois, uma proporção considerável não possui esse conhecimento (BRASIL, 2015).

As diretrizes para implantação do Projeto Saúde e Prevenção nas Escolas orientam que cabe à escola:

Construir espaços de diálogo entre adolescentes, jovens, professores, profissionais de saúde e comunidade é, comprovadamente, um importante dispositivo para construir resposta social com vistas à superação das relações de vulnerabilidade às DST, à infecção pelo HIV e à aids, assim como à gravidez não planejada. Para tanto, as ações desenvolvidas devem ir além da dimensão cognitiva, levando em conta aspectos subjetivos, questões relativas às identidades e 
às práticas afetivas e sexuais no contexto das relações humanas, da cultura e dos direitos humanos (BRASIL, 2008, p. 15).

A sexualidade é inerente à vida humana por ser um tema gerador de tabus, por isso, a escola precisa internalizar e normalizar este tema a fim de esclarecer dúvidas como citado por Brasil (2008) abordando-o em todas as suas dimensões de forma ampla e clara. O papel da escola é de extrema relevância no sentido de desconstruir o preconceito inserido a identidade de gênero de forma efetiva no contexto escolar de acordo com Werebe (1998), que nos diz o conhecimento está diretamente aliado a prevenção a educação sexual, num sentido amplo, processo global, não intencional, sempre existiu, em todas as civilizações, no decurso da história da humanidade, de maneira consciente ou não, com objetivos claros ou não, assumindo características variadas, segundo a época e as culturas.

Saber identificar as ISTs, suas formas de contágio e a forma de contágio, e a possibilidade de cura é imprescindível para que o indivíduo exerça sua sexualidade de forma segura visando a proteção da saúde, mas também para que saiba como agir diante de uma possível exposição e infecção tornando-se assim, capaz de tomar as medidas adequadas (BRASIL, 2015).

Nesse sentido, Ribeiro (1990) destaca que:

A educação leva o homem à sua perfeição, a compreender a realidade social, a fim de transformá-la e procurar soluções aos desafios do mundo com uma dimensão holística. Neste sentido, vê-se que a educação sexual surge da necessidade de um esclarecimento à população "em função da repressão estabelecida pela cultura e pela sociedade". (RIBEIRO, 1990, p.5).

Conforme a citação supracitada a repressão à sexualidade se constitui em um risco a vida, pois é preciso que o estudante conheça todas as dimensões do seu organismo para efeito da manutenção da própria saúde (RIBEIRO, 1990).

A Figura 4 ilustra os dados referente aos aspectos relacionados às formas de contágio e de prevenção das ISTs. 
Figura 4: Formas de contágio e prevenção das ISTs.

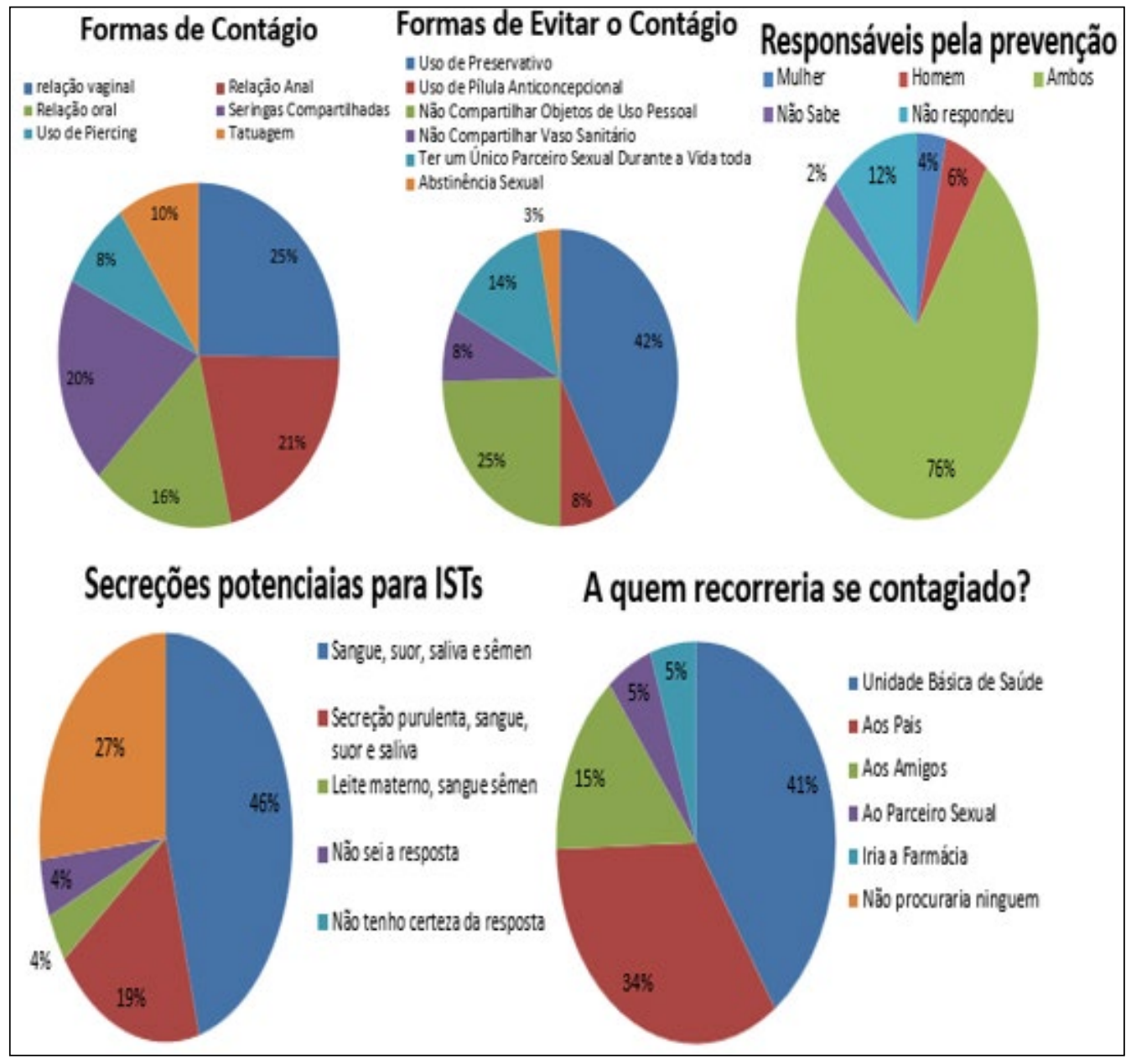

Fonte: Dados coletados na pesquisa (2020).

Ao questionar os estudantes entrevistados sobre a responsabilidade de prevenir as ISTs $76 \%$ dos entrevistados respondeu que homens e mulheres têm a mesma responsabilidade, portanto compete a ambos a prevenção, no entanto uma parcela significativa cerca de $12 \%$ não respondeu à pergunta, $\mathrm{o}$ que pode indicar desconhecimento acerca do tema, e isso deve ser considerado pela escola no sentido de elucidar as dúvidas que porventura existem acerca do tema.

Entre os entrevistados $4 \%$ respondeu que a prevenção é exclusividade da mulher enquanto $6 \%$ consideram essa responsabilidade exclusiva do homem, $2 \%$ alega não saber de quem é a responsabilidade da prevenção. Diante dos dados é importante refletir sobre o que aponta Sousa et al. (2017, p. 2293): 
A prevalência das IST em adolescentes/ jovens pode advir do fato de eles desconhecerem os métodos de prevenção e contágio, ou não atribuírem a devida importância à situação, mesmo sendo constantemente informados, continuando com o comportamento de risco. As adolescentes ainda caracterizam a sexualidade como etapa do desenvolvimento, podendo estar relacionada aos atos sexuais ou ao relacionamento a dois, marcando o início da vida sexual.

Quanto à vulnerabilidade dos adolescentes em relação as ISTs um dos principais fatores é a falta de informação a exemplo do que aponta os dados acima, diante do início da vida sexual e seus inúmeros desafios é importante que o acesso à informação seja facilitado em qualquer veículo de informação, pois ao dispor de informação é possível ajustar a conduta no sentido de tomar as medidas mais seguras para a prevenção com vistas a promoção de sua saúde e de seus parceiros (BRASIL, 2015; SOUSA et al., 2017).

Observa-se no gráfico acima um aspecto importante que deve ser considerado é o fato de apenas $42 \%$ dos entrevistados associar o uso do preservativo para prevenir as ISTs é necessário destacar que o papel fundamental da escola deve ser de oferecer subsídios para uma educação emancipadora e esta não é aquela que reproduz o conhecimento, mas sim aquela que transforma o conhecimento por meio da aplicabilidade como nos diz Freire "[...] um processo pelo qual o educador convida os educandos a reconhecer e desvelar a realidade criticamente" (FREIRE, 1985, p. 125).

Corroborando com Freire (1985), a educação tem sentido quando o estudante consegue relacionar o conteúdo ao seu cotidiano, voltando para vulnerabilidade quanto as ISTs, não basta saber da existência do preservativo e que pode evitar a transmissão de doenças é necessário saber quais doenças e mais identificar se o seu comportamento é um comportamento de risco, portanto ter criticidade ao analisar seu modo de vida.

A escola precisa emancipar o estudante para que ele seja capacitado em aliar teoria e a pratica, no caso especifico saber identificar quais são as secreções com potencial infectante e neste sentido os entrevistados responderam $46 \%$ responderam que sangue, suor, saliva e sêmen são substancias com potencial infectante, $19 \%$ secreção purulenta, sangue, suor e saliva. Ao analisar as respostas percebe-se que os entrevistados ainda não identificam com certeza as substâncias com potencial infectante.

Ao ser questionado sobre a quem recorreria ao ser infectado $41 \%$ responderam que buscariam uma unidade de saúde e neste sentido compreendese que o a informação a respeito do quadro, no entanto 34\% recorreriam aos pais para auxiliá-los.

Os estudantes demonstram que possuem informações a respeito de como cuidar da saúde, no entanto é necessário identificar o debate para que nenhum jovem estudante adoeça por falta de informação acerca das ISTs pois 
a vulnerabilidade constitui-se em um potencial risco a saúde (BRASIL, 2015; SOUSA et al., 2017).

\section{CONSIDERAÇÕES FINAIS}

O estudo apresenta alguns dados que cabem reflexão acerca do papel da escola e da família diante da formação do indivíduo no que tange o tema sexualidade e prevenção de ISTs e nesse sentido preservar saúde pública.

A escola cabe a função de formar e informar com a perspectiva de uma formação integral do sujeito, tratando-se de ISTs em face dos riscos à saúde que as mesmas podem causar é importante neste momento que a escola e seus atores não tenham receios ou reservas para debater com clareza todos os temas inerentes ao ser humano, principalmente os temas voltados a sexualidade e a saúde pública.

É necessário defender uma escola laica, livre e democrática onde todos os conteúdos sejam enfatizados de acordo com a avaliação diagnóstica do educador, neste sentido entende-se que projetos semelhantes a escola sem partido se constitui na censura e no cerceamento do papel da escola.

\section{REFERÊNCIAS}

AQUINO, Camila; MARTELLI, Andrea Cristina. Escola e Educação Sexual: Uma Relação Necessária. IX ANPED SUL, 2012.

BARDIN, Laurence. Análise de conteúdo. São Paulo: Edições 70, 2012.

BRASIL. Constituição (1988). Constituição [da] República Federativa do Brasil. Brasília, DF: Senado Federal, 1988.

BRASIL. Ministério da Saúde. Secretaria de Vigilância em Saúde. Departamento de DST, Aids e Hepatites Virais. Protocolo Clínico e Diretrizes Terapêuticas para Atenção Integral às Pessoas com Infecções Sexualmente Transmissíveis / Ministério da Saúde, Secretaria de Vigilância em Saúde, Departamento de DST, Aids e Hepatites Virais. Brasília: Ministério da Saúde, 2015.

BRASIL, Ministério da Educação. Secretaria de Educação Fundamental. Parâmetros curriculares nacionais: apresentação dos temas transversais: ética. 2. ed. Rio de Janeiro:DP\&A, 2000. v. 8.

BRASIL. Ministério da Saúde. Coordenação Nacional de DST e Aids. Prevenir é sempre melhor. Brasília: Ministério da Saúde, 2000. 93p.

BRASIL. Ministério da Saúde. Secretaria de Vigilância em Saúde. Programa Nacional de DST e Aids. Diretrizes para implantação do Projeto Saúde e Prevenção nas Escolas. Brasília: Ministério da Saúde, 2008. 
BRITTO, Tatiana Feitosa de. O que os professores (não) podem dizer? A experiência canadense e a "Escola sem Partido" Revista Brasileira de Educação. v. 24, n. 2, 2019.

COUTINHO, Maria de Fátima Goulart. Crescimento e Desenvolvimento na Adolescência. Revista de Pediatria SOPERJ - suplemento, p. 28-34, 2011.

FREIRE, Paulo. Educação como prática da liberdade. 23. ed. Rio de Janeiro: Paz e Terra, 1999.

FREIRE, Paulo. Pedagogia do oprimido. 4. ed. Rio de Janeiro: Paz e Terra, 1977.

FREIRE, Paulo. The politics of education: culture, power, and liberation. Westport, CT: Bergin and Garvey, 1985. 209 p.

FREUD, Sigmund Schlomo. Três ensaios sobre a teoria da sexualidade. Rio de janeiro: Imago, 1969. (Pequena Coleção das Obras de Freud, Livro 2).

FOUCAULT, Michel. História da sexualidade I: a vontade de saber. Rio de Janeiro: Graal, 1988.

GIL, Antônio Carlos. Métodos e Técnicas de Pesquisa Social. 6. ed. São Paulo: Atlas, 2010.

INSTITUTO BRASILEIRO DE GEOGRAFIA E ESTATÍSTICA. Censo demográfico 2010: Abaetetuba, PA - pirâmide etária [Internet]. Rio de Janeiro: IBGE; 2010 [citado 2014 set 20]. Disponível em: http:/ / cidades.ibge.gov.br/xtras/perfil.php?lang=\&cod mun=150010\&search=para $\mid$ abaetetuba $\mid$ infograficos:-informacoes-completas. Acesso em: 13 mar. 2020.

LIRA, Alexandre Tavares do Nascimento. A legislação da educação no Brasil durante a ditadura militar (1964-1985): um espaço de disputas / Alexandre Tavares do Nascimento Lira. - 2010

MAIA, Ana Cláudia Bortolozzi; RIBEIRO, Paulo Rennes Marcal. Educação sexual: princípios para ação. Doxa: Revista Brasileira de Psicologia e Educação, Araraquara, v. 15, n. 1, p. 75-84, 2011.

MEIRA, Renan Devitto; SANTANA Luciana Teófilo. Sexualidade Na Perspectiva Histórico-Cultural: Primeiras Aproximações. Trilhas Pedagógicas, v. 4, n. 4, p. 160181, Ago. 2014.

MOISES, Julieta Seixas; BUENO, Sonia Maria Vilela. Compreensão sobre sexualidade e sexo nas escolas segundo professores do ensino fundamental. Revista Escola de Enfermagem USP, São Paulo, v. 44, n. 1, 2010. Disponível em: <http:/ / www.scielo. br/scielo.php?pid=S0080-62342010000100029\&script=sci_arttext $>$. Acesso em: 15 fevereiro 2020. 
NUNES, Maria José. A percepção do adolescente sobre sua sexualidade frente às Doenças sexualmente transmissíveis/AIDS. Dissertação de mestrado. Escola de Enfermagem da Universidade Federal de Minas Gerais. Belo Horizonte: 2000.

RIBEIRO, Karla Carolina Silveira. Adolescência e sexualidade: vulnerabilidade às DSTS, HIV / AIDS e a gravidez em adolescentes paraibanos / Karla Carolina Silveira Ribeiro. --João Pessoa: [s.n.], 2010.

RIBEIRO, Paulo Rennes Marçal. Educação sexual além da informação. São Paulo: EPU, 1990.

SANTANA, Luther King de Andrade. Religião e Mercado: a mídia empresarialreligiosa. Revista de Estudos da Religião, São Paulo, v. 1, n.1, p. 54-67, 2005.

SAVIANI, Demerval. Pedagogia histórico-crítica: primeiras aproximações. 3. ed., São Paulo: Cortez Editora \& Autores Associados, 1992 (Col. Polêmicas do Nosso Tempo, v. 40).

SOUSA, Catarina Praciano de. et al. Adolescentes: Maior Vulnerabilidade às IST / AIDS? Adolescents: Larger Vulnerability TO STI/AIDS? RETEP - Rev. Tendên. da Enferm. Profis, v.9, n. 4, p. 2289-2295, 2017.

TUCKMANTEL. Maísa Maganha. A sexualidade vai à escola: da informação biológico-reprodutiva à formação do sujeito ético. Revista Trilhas Pedagógicas, Pirassununga, v. 1, n. 1, p. 38-62, ago. 2011.

VASCONCELOS, Naumi. Os Dogmatismos Sexuais. Rio de Janeiro, Ed. Paz e Terra, 1971.

VIEIRA, Kay Francis Leal; COUTINHO, Maria da Penha de Lima; SARAIVA, Evelyn Rúbia de Albuquerque. A Sexualidade Na Velhice: Representações Sociais De Idosos Frequentadores de Um Grupo de Convivência. Psicol. cienc. prof. [online]. v. 36, n. 1, p.196-209, 2016.

VYGOTSKY, Lev Semionovitch. A formação social da mente: o desenvolvimento dos processos psicológicos superiores. 4. ed. São Paulo: Martins Fontes, 1991.

WEREBE, Maria José Garcia. Sexualidade, Política e Educação. Campinas: Editora Autores Associados, 1998. 